\title{
Light-sensitive heterocyclic compounds for information nanotechnologies
}

\author{
Valery A. Barachevsky, ${ }^{\text {a* }}$ Yury P. Strokach, ${ }^{\text {a }}$ Yury A. Puankov, ${ }^{\text {a Olga I. Kobeleva, }}{ }^{\text {a }}$ \\ Tatyana M. Valova, ${ }^{\text {a }}$ Konstantin S. Levchenko, ${ }^{\text {b Vladimir N. Yaroshenko, }}{ }^{\text {b }}$ \\ and Michail M. Krayushkin ${ }^{b}$ \\ ${ }^{a}$ Photochemistry Center, Russian Academy of Sciences, Moscow, Russia \\ ${ }^{b}$ N.D. Zelinsky Institute of Organic Chemistry, Russian Academy of Sciences, Moscow, Russia \\ E-mail: barva@photonics.ru
}

\begin{abstract}
Spectral-kinetic studies have been analyzed for a number of photochromic and irreversible lightsensitive heterocyclic compounds and evaluated as components of advanced information nanotechnologies, in recording media for working- and archival- three-dimensional (3D) optical memory and for photocontrolled metal chemosensors.
\end{abstract}

Keywords: Photochromic compounds, photofluorescent compounds, dihetarylethenes, quinones, fulgimides, spiro- compounds, chromones, optical memory, chemosensors

\section{Introduction}

The progress in the information technologies calls for increases in the information capacity of the recording media and the rate of information processing, and for extension of their functional capabilities. Analysis of the state-of-the-art research into the design of recording media ${ }^{1}$ shows that the limiting information capacity of magnetic disks can be increased to 20 Gbytes. The data processing rate may be equal to 1 Gbyte/s.

Apart from magnetic disks, optical disks (ODs) are used for archival information storage of the CD type (I), which ensure multiple readouts of the optical data recorded in a recording studio, as well as WORM (II), which ensure a single data recording and multiple data readout directly in a PC. For multiple optical data writing, rewriting, and readout the WERM type (III) reverse OD was designed.

Optical data recording on most of the known ODs is based on thermo-induced transformation of compounds. The information capacity of these ODs is about 4.7 Gbytes when a semiconductor laser with a radiation wavelength of $650 \mathrm{~nm}$ is used for data readout. New ODs developed by the Blu-ray Disc Association possess a record information capacity equal to 25 Gbytes for one- 
sided- and 50 Gbytes for two-sided- (DVD) data media. This is attained by the use of a semiconductor laser with a shorter wavelength $(405 \mathrm{~nm})$, an optical system with a digital aperture of $0.7 / 0.8$, and a 0.1 -mm thick light-sensitive layer.

The prospects for increasing the information capacity of ODs are related to the design of multilayer light-sensitive recording media for bitwise data recording, and thick (more than 2-mm thick) light-sensitive layers for holographic data recording. These ODs can provide a 3D- optical memory of more than 1 Tbyte by data recording and display in different layers of the recording medium in the case of bitwise optical memory, or under different incidence angles of the activating and restoring laser radiation in the case of holographic optical memory. Lightsensitive organic recording media based on photochemical transformations of organic compounds are meant as the recording layers for such ODs. These media have, in principle, a higher resolution than the currently used temperature-sensitive materials.

In recent years, particular importance has been given to information technologies for the design of new environmental monitoring systems - in particular, chemosensors of various types, especially nanochemosensors, which ensure a sharp decrease in the sensor dimensions.

The purpose of this study was to reveal the possibility of using the synthesized photochromic and irreversible light-sensitive heterocyclic organic compounds for the development of lightsensitive materials suitable for the design of advanced optical memory devices and photocontrolled chemosensors with high information capacity.

\section{Results and Discussion}

\section{Photochromic heterocyclic compounds for OD recording media}

By photochromism, one means the ability of a compound to change reversibly, on exposure to optical irradiation, its absorption spectrum in the visible region, i.e., color, and also other properties caused by the formation of what is actually a new compound. ${ }^{2-4}$

During a photochromic process, a substance that has absorbed optical irradiation is transformed from the initial state $\mathbf{A}$ into a so-called photoinduced state $\mathbf{B}$ having a different absorption spectrum and a particular lifetime. The back- transition of state $\mathbf{B}$ into state $\mathbf{A}$ occurs spontaneously at the expense of intrinsic energy and can be considerably accelerated by heating or under the action of light, which is absorbed by the form $\mathbf{B}$ :

\section{Scheme 1}

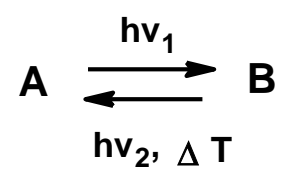

It was proposed to use photochromic transitions between two spectrally distinguishable states for the design of optical memory. ${ }^{5}$ However, this proved possible only after the synthesis of 
photochromic compounds that undergo photochromic but thermally irreversible transformations. ${ }^{6}$ For the development of bitwise 3D working optical memory (WERM) ${ }^{7}$ it is planned to use two-photon photochromism, ${ }^{8}$ which ensures layer-by-layer optical data- recording in a multilayer photochromic recording medium. Photochromic compounds suitable for this application should show a low photodegradation efficiency, thus ensuring high recurrence of optical data writing and rewriting, high two-photon absorption cross-sections and, hence, high light sensitivity, and should also allow non-destructive readout of optical data. ${ }^{9}$ These photochromic compounds are few, and are mainly diarylethenes (I), ${ }^{9}$ fulgides and fulgimides (II),${ }^{10}$ or phenoxy derivatives of quinones (III). ${ }^{11}$ All compounds of these types undergo reversible photoinduced valence isomerization. The diarylethenes, I, and fulgimides, II, undergo reversible phototransformations between open and cyclic forms, and the phenoxyquinones III are interconverted between ana- and para- quinone forms.

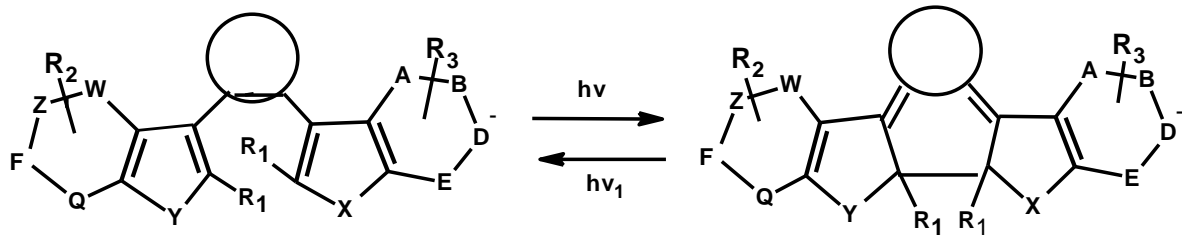

I A

I B

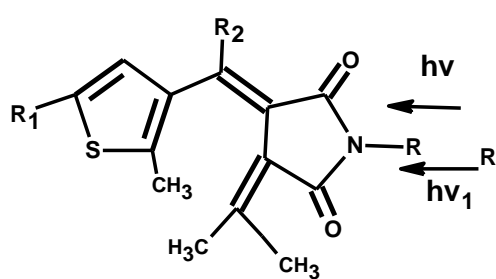

II A

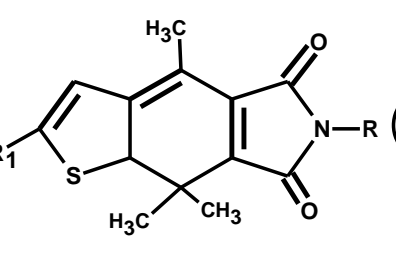

II B

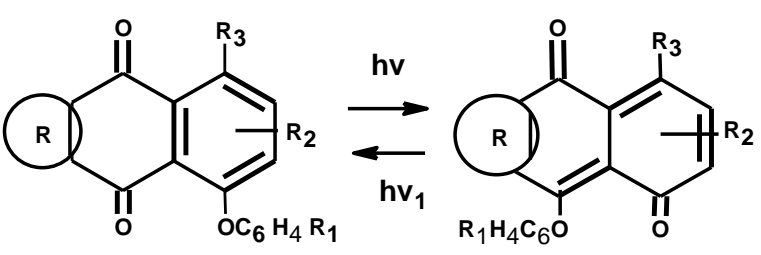

III A

III B

\section{Scheme 2}

In this paper, we present the spectral-kinetic properties of only dihetaryl-ethenes and fulgimides, which are considered as the most promising thermally irreversible photochromic components for recording media.

\section{Dihetarylethenes $^{12-31}$}

The photochromic properties of more than 180 dihetarylethenes with various bridging fragments (Figure 1) were studied by the spectral- kinetic method. The study showed that all of these photochromic dihetarylethenes are thermally irreversible. Indeed, storage of their irradiated solutions in the dark for a month did not result in any significant changes in the UV-induced absorbance at the absorption maxima of the cyclic form. The results of spectral-kinetic studies of a series of symmetrical compounds of these sub-classes with thienyl substituents are summarized in Table 1. 


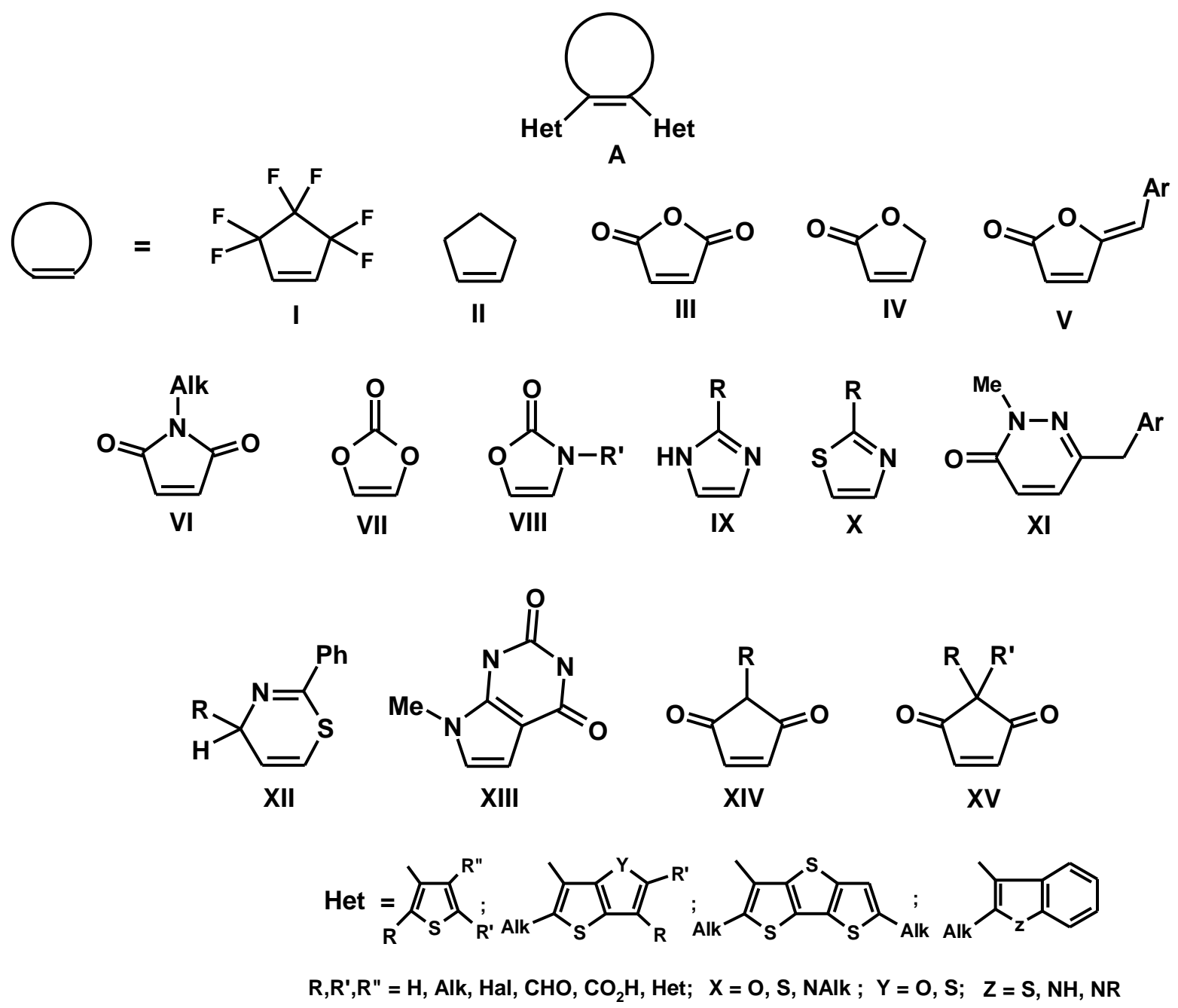

Figure 1

Analysis of the experimental results shows that the open form is responsible for UV absorption bands with maxima at $240-400 \mathrm{~nm}$, which meet the conditions for their use as lightsensitive components of recording media. The longest-wavelength absorption bands of the open form were found for compounds of subclasses V, VI, XIV and XV. The effect of the structure of the bridge is most pronounced in the absorption spectra of the cyclic form. The variation range is 420-625 nm. As examples, Figures 2-4 show the photo-induced changes in the absorption spectra for particular compounds. The pronounced difference between the spectral characteristics of the open and cyclic forms of the dihetarylethenes opens up prospects for the design of fourdimensional (4D) optical memory for data recording and readout, not only in different sites of the bulk of a recording medium but also at different laser radiation wavelengths and, hence, an increase in the information capacity of ODs. 
Table 1. Spectral-kinetic characteristics for dihetarylethenes in toluene ${ }^{*, \dagger}$

\begin{tabular}{|c|c|c|c|c|c|c|}
\hline Code & Structure & $\lambda_{\mathrm{A}}, \mathrm{nm}$ & $\lambda_{\mathrm{B}}, \mathrm{nm}$ & $\Delta \mathrm{D}_{\text {max }}^{\mathrm{B}}$ & $\mathrm{k}_{\mathrm{AB}} / \mathrm{k}_{\mathrm{BA}}$ & $\mathrm{t}_{0.5} ._{\text {photodeg }} / \mathrm{s}$ \\
\hline I. 1 & & 290 & 625 & 1.44 & 21.0 & 70 \\
\hline IV.2 & & 300 & 515 & 0.35 & 1.4 & 90 \\
\hline V. 3 & & 365 & 550 & 0.55 & 6.2 & 120 \\
\hline VI.4 & & 400 & 505 & 0.26 & 5.2 & 20 \\
\hline VII.5 & & $<300$ & 450 & 0.41 & 1.1 & 25 \\
\hline VIII.6 & & 290 & 455 & 0.46 & 1.9 & 8 \\
\hline IX.7 & & $\begin{array}{l}240 \\
300\end{array}$ & $>350(\mathrm{sh})$ & $\begin{array}{r}F \\
\text { photode }\end{array}$ & $\begin{array}{l}\text { ast } \\
\text { gradation }\end{array}$ & 28 \\
\hline X.8 & & 300 & 515 & 0.30 & 0.7 & 105 \\
\hline XI.9 & & 325 & 585 & 1.2 & 1.4 & 70 \\
\hline
\end{tabular}


XII.10

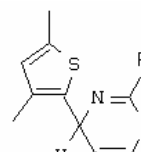

$$
\begin{array}{lllll}
<300 & 470 & 0.28 & 2.1 & >300 \\
<300 & 420 & 0.68 & 2.5 & 100
\end{array}
$$

XII.11

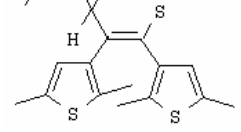

$\begin{array}{lllll}<300 & 420 & 0.68 & 2.5 & 100\end{array}$

470

XIII.12
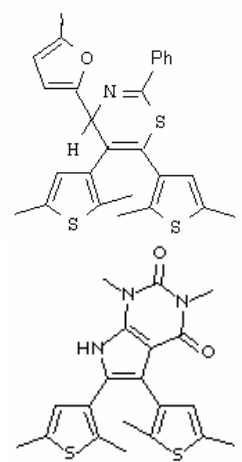

290

535

1.8

23.0

15

XIII.13*

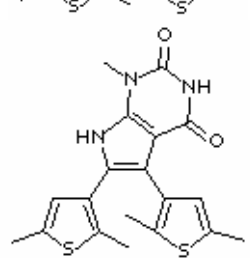

13.8

10

XIII.14*

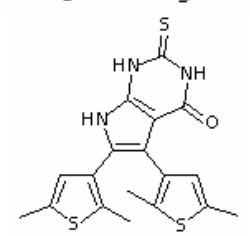

XIV.15

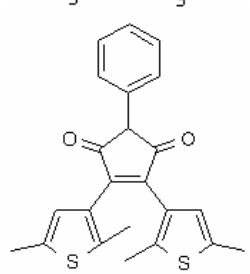

XV.16

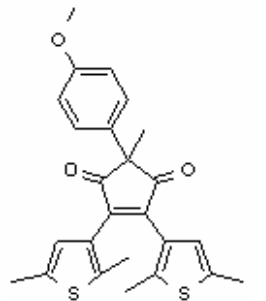

375

595

0.7

5.6

55

*In acetonitrile. ${ }^{\dagger}$ Note: $\lambda_{\mathrm{A}}$ and $\lambda_{\mathrm{B}}$ are the absorption maxima for open (A) and cyclic (B) forms, respectively; $\Delta \mathrm{D}^{\mathrm{B}}$ max is the greatest photoinduced change in the absorbance at the absorption maximum of the cyclic form $B$ in the photoequilibrium state; $k_{A B} / k_{B A}$ is the ratio of the photocoloration and photo-bleaching rate constants; $\mathrm{t}$. 0.5 photodeg is the time taken for the absorbance attained in the photostationary state at the absorption maximum of the cyclic form to halve under continuous irradiation with unfiltered light from the DRSh-250 lamp. 


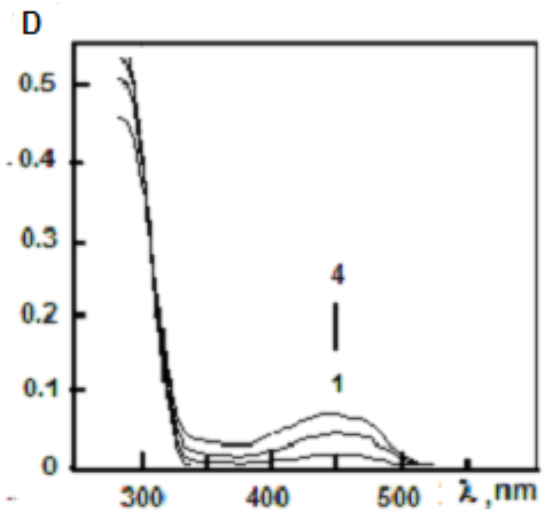

Figure 2. Absorption spectra for the compound VII.5 in toluene before (1), and after consecutive UV irradiation (2-4).

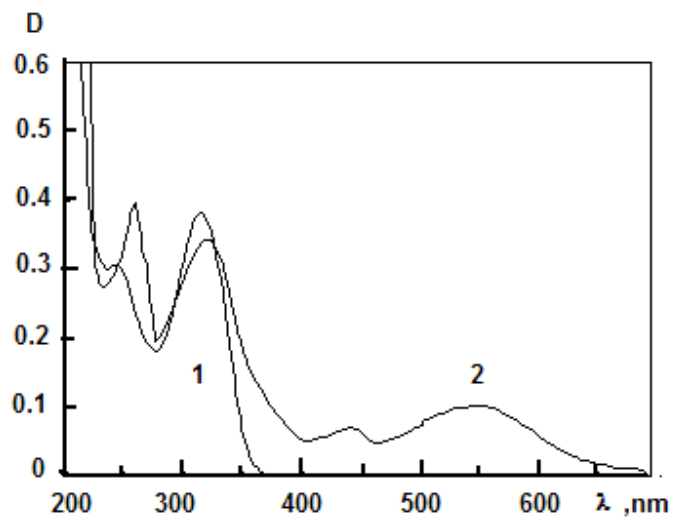

Figure 3. Absorption spectra for compound XIII.14 in acetonitrile before (1), and after UV irradiation (2).

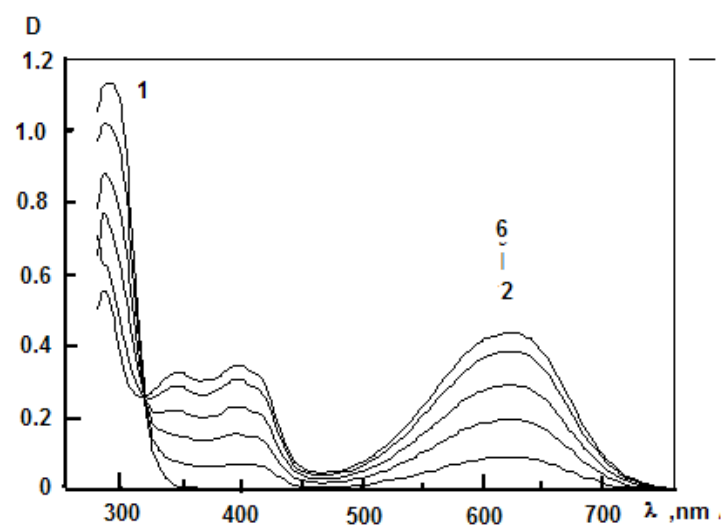

Figure 4. Absorption spectra for the compound I.I in toluene before (1), and after consecutive UV irradiation (2-6). 


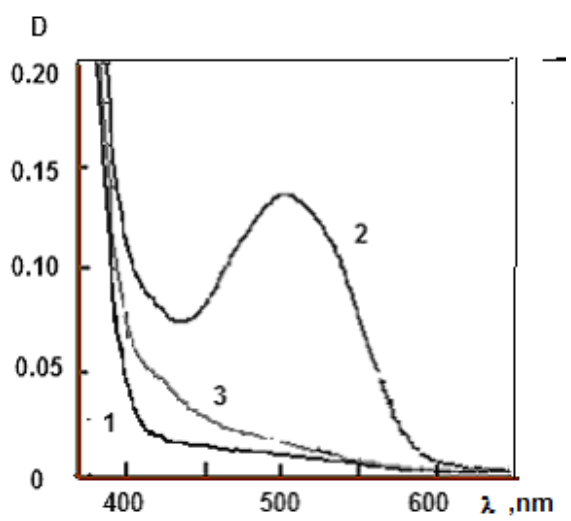

Figure 5. Absorption spectra for photochromic polymer (Scheme 4) in polycarbonate (4 mass.\%) before (1), and after UV (2), and visible (3) irradiation.

Judging by the photoinduced change in the absorbance at the wavelength of the absorption maximum for the cyclic form $\left(\Delta \mathrm{D}^{\mathrm{B}}{ }_{\text {max }}\right)$, the highest light-sensitivity was shown by compounds of sub-classes I, XI and XIII. As can be seen from Table 1, the ratio of the photocoloration and photobleaching constants, which determine the efficiency of these processes, can vary from 3 to 21 depending on the structures of the bridging fragments. An exceptionally important characteristic of photochromic compounds meant for the design of recording media is the recurrence of photochromic transformations. Judging by the photodecomposition efficiency $\left(\mathrm{t}_{0 .} 5^{\text {photodeg }}<70 \mathrm{~s}\right)$, the majority of the studied compounds are unsuited for the desired application. Our subsequent studies demonstrated that the stability of dihetarylethenes against irreversible phototransformation increases appreciably for almost all of these compounds when the thienyl groups are replaced by symmetric benzothienyl substituents (Table 2).Comparative analysis, taking into account all spectral-kinetic parameters, resulted in the selection of compounds of sub-classes I and II as the light-sensitive components of photochromic recording media for 3D bitwise working optical memory.

In view of the necessity of increasing the thermal stability of the recorded optical data caused by the diffusion of photochromic molecules in the polymer layer, and of increasing the concentration of light-sensitive components in the polymer layer, the possibility of preparing photochromic polymers was demonstrated. ${ }^{23,24}$ Figure 5 presents spectroscopic characteristics of the open and cyclic forms for this photochromic polymer are shown in Figure 6.

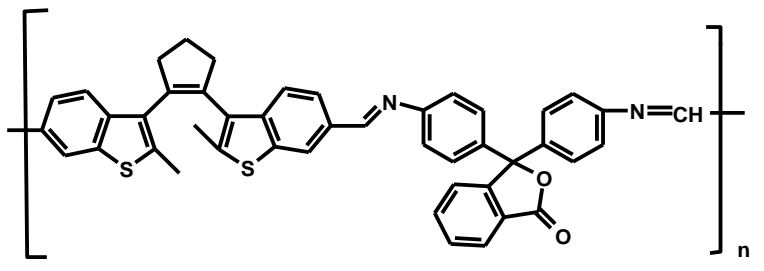

\section{Figure 6}




\section{Fulgimides (XVI) ${ }^{26-33}$}

As for dihetarylethenes, our study of the kinetics of thermal relaxation of the photoinduced cyclic form B to the initial open form A showed that both forms are thermally stable for at least one month when their solutions are stored in the dark in tightly plugged vessels. The spectralkinetic characteristics for the studied fulgimides are summarized in Table 3. As for dihetarylethenes, the absorption spectra of the open forms A are in the UV region for all compounds $(250-335 \mathrm{~nm})$. As an example, Figure 7 shows the absorption spectra of the initial and photoinduced forms for compound XVI.1. It can be seen from Table 5 that for monofulgimides (XVI.1-XVI.5), the position of the absorption maximum of the open form depends little on the structure of the compound: in particular, an increase in the electron-withdrawing properties of the substituent $\mathrm{R}$ induces a slight hypsochromic shift. The cyclic forms of these compounds absorb in the visible region, with $\lambda_{\max }$ at 520-540 nm (Figure 7, Table 3). However, unlike the open form, as the electron-withdrawing properties of compounds are enhanced, the absorption band of the cyclic isomer is shifted to longer wavelengths relative to that of compound XVI.1. Analysis of the photocoloration kinetics for solutions of fulgimides in toluene shows that the efficiency of photocoloration decreases when electron-withdrawing substituents are introduced into the phenyl fragment. The light resistance of these compounds increases simultaneously.

The synthesized bis-fulgimides (XVI.6-XVI.9) are similar to mono-fulgimides in their spectral- kinetic properties and have close absorption maxima for both open- and photo-induced forms, except for compound XVI.4. This means that the phenyl rings and the heterocycle located between them hardly participate in the conjugation of two fulgimide moieties. According to the magnitude of the photoinduced change in the absorbance at the absorption maximum wavelength of the cyclic form, the light-sensitivity of the compounds hardly depends on the structure of the spacer between the fulgimide fragments.

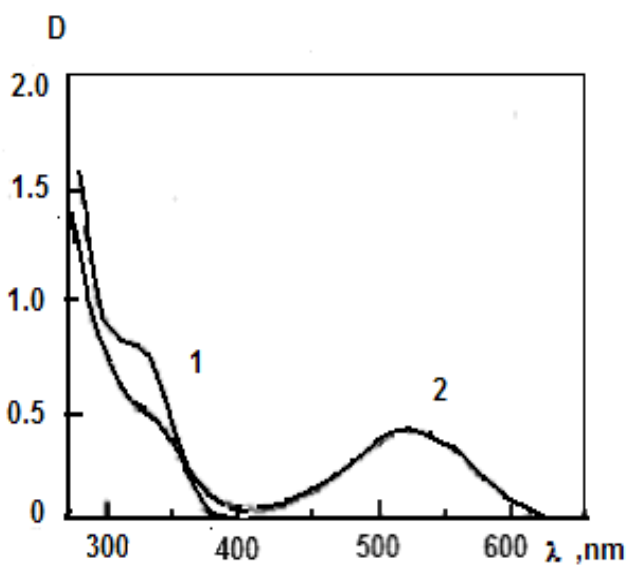

Figure 7. Absorption spectra for the compound XVI.1 in toluene before (1) and after consecutive UV irradiation (2). 
Unlike compounds XVI.6-XVI.9, the absorption band of the cyclic form of bis-fulgimide F10 is shifted by $32 \mathrm{~nm}$ to shorter wavelengths with respect to the analog XVI. 6 (Figure 8). The rate of photobleaching thus increases, and the light-resistance is enhanced. By analogy with dihetarylethenes, this may be a result of replacement of the thienyl fragments by benzothienyl ones. Attention is attracted by the presence of an isobestic point in the series of absorption spectra for both this and other fulgimides, which is indicative of the inter-conversion of only open- and cyclic- forms of this photochromic compound. The E-Z isomerization inherent in fulgides seems to be inefficient for these fulgemides.

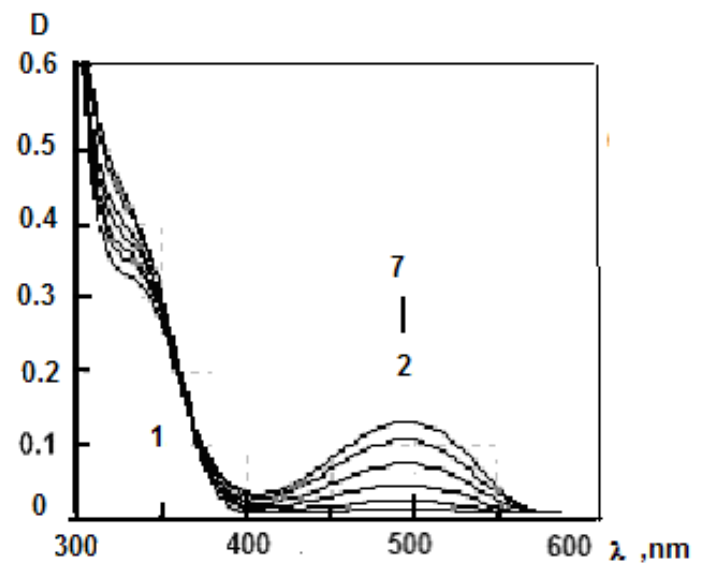

Figure 8. Absorption spectra for the compound XVI.10 in toluene before (1), and after, consecutive UV irradiation (2-7).

As can be seen from comparison of the spectral-kinetic characteristics of the dihetarylethenes (Table 2) and fulgimides (Table 3) possessing the best properties, the latter are inferior in their stability against irreversible phototransformations and, hence, in the recurrence of photochromic transformations.

In conclusion, it should be noted that thermally irreversible photochromic spiropyrans, dihetarylethenes, and quinones can be used as photosensitizers in photo-polymerizable recording media suitable for the design of 3D holographic archive optical memory. ${ }^{34}$ Their use markedly facilitates fixation of holograms and ensures the possibility of optical data addition on the OD. 
Table 2. Comparative spectral-kinetic characteristics for dihetarylethenes in toluene

\begin{tabular}{|c|c|c|c|c|c|c|}
\hline Code & Structure & $\begin{array}{l}\lambda_{\mathrm{A}} \\
\mathrm{nm}\end{array}$ & $\begin{array}{l}\lambda_{\mathrm{B}} \\
\mathrm{nm}\end{array}$ & $\Delta \mathrm{D}^{\mathrm{B}}{ }_{\max }$ & $\mathrm{k}_{\mathrm{AB}} / \mathrm{k}_{\mathrm{BA}}$ & $\mathrm{t}_{0.5}{ }^{\text {photodeg }}, \mathrm{s}$ \\
\hline I. 1 & & 290 & 625 & 1.44 & 21.0 & 70 \\
\hline 1.17 & & 330 & 555 & 1.10 & 1.0 & 1040 \\
\hline II.18 & & 340 & 495 & 1.75 & 1.3 & 750 \\
\hline VI.4 & & 400 & 505 & 0.26 & 5.2 & 20 \\
\hline VII.5 & & $<300$ & 450 & 0.41 & 1.1 & 25 \\
\hline VII.20 & & 300 & 450 & 1.46 & 0.6 & 60 \\
\hline VIII.6 & & 290 & 455 & 0.46 & 1.9 & 8 \\
\hline VIII.21 & & 300 & 455 & 0.38 & & 24 \\
\hline
\end{tabular}


Table 3. Comparative spectral-kinetic characteristics for fulgimides in toluene

\begin{tabular}{|c|c|c|c|c|c|c|}
\hline Code & Structure & $\lambda_{\mathrm{A}}, \mathrm{nm}$ & $\lambda_{\mathrm{B}}, \mathrm{nm}$ & $\Delta \mathrm{D}_{\text {max }}^{\mathrm{B}}$ & $\mathrm{k}_{\mathrm{AB}} / \mathrm{k}_{\mathrm{B}}$ & $\mathrm{t}_{0.5^{\text {photodeg }} / \mathrm{s}}$ \\
\hline XVI. 1 & & $\begin{array}{l}250, \\
325\end{array}$ & 522 & 0.75 & $\frac{\mathrm{A}}{1.2}$ & 25 \\
\hline & $\mathrm{R}=\mathrm{Ph}$ & & & & & \\
\hline XVI.2 & $\mathrm{R}=\mathrm{NH}_{2}$ & 325 & 520 & 0.9 & 1.0 & 70 \\
\hline XVI.3 & $\mathrm{R}-\mathrm{NHCO}_{2} \mathrm{Bu}$ & $\begin{array}{l}230 \\
280 \\
330\end{array}$ & 530 & 0.70 & 0.9 & 40 \\
\hline XVI.4 & $\mathrm{R}=\mathrm{NPhCl}$ & 290 & 540 & 0,61 & 0.3 & 95 \\
\hline XVI.5 & $\mathrm{R}=\mathrm{NphNO}_{2}$ & 305 & 540 & 0,65 & 0.4 & 100 \\
\hline XVI.6 & & $\begin{array}{l}250 \\
330\end{array}$ & 528 & 1.2 & 0.8 & 30 \\
\hline XVI.7 & & $\begin{array}{c}285 \\
335 \mathrm{sh}\end{array}$ & 530 & 1.5 & 0.4 & 50 \\
\hline XVI. 8 & & $\begin{array}{c}285 \\
335 \mathrm{sh}\end{array}$ & 530 & 1.5 & 0.4 & 50 \\
\hline XVI. 9 & & 310 & 530 & 1.1 & 0.4 & 50 \\
\hline XVI.10 & & 335 & 495 & 0.75 & 0.1 & 220 \\
\hline
\end{tabular}

Irreversible photofluorescent heterocyclic organic compounds for OD recording media

The photochromic heterocyclic compounds considered above are meant for the use as lightsensitive components of OD recording media for implementation of the 3D- bitwise working optical memory (WERM ODs). For the design of the WORM ODs recording media for 3D bitwise archive optical memory, light-sensitive photofluorescent materials appear most promising. The development of these media is based on heterocyclic organic compounds that have no luminescence in their initial form but form fluorescent photoproducts. Unfortunately, development of recording media of this type has not received adequate attention, despite the high demand for WORM ODs. The few studies along this line are represented by the development of 
organic photoluminescent layers by the Constellation company, USA ${ }^{35}$ and by the Call/Recall company, USA. ${ }^{36,37}$. Irreversible light-sensitive recording media with photoinduced fluorescence have been developed, based on irreversible photochemical reactions of aromatic azides, diarylamine and tetrabromomethane, as well as haloacridine and naphthacenequinone derivatives. $^{38-41}$

Recently, we have performed research into the synthesis and spectral luminescent properties of light-sensitive compounds of the chromone class XVII (Figure 9), which undergo irreversible photochemical transformations according to Scheme 3. The results of spectral kinetic photochemical studies of some of the synthesized compounds are presented in Table 4 . Figure 10 shows typical absorption spectra of the initial compound and its irreversible photoproduct and the fluorescence spectrum of the latter.<smiles>[R]c1cc([R])c(-c2oc3c(c(=O)c2C(N)=O)CCCC3)o1</smiles><smiles>[R]c1oc(-c2oc3c(c(=O)c2C(=O)c2sc([R])c([2H])c2[2H])CCCCC3)c([R])c1[2H]</smiles>

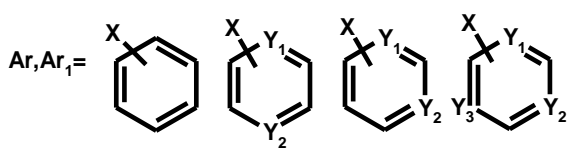<smiles></smiles><smiles>[Y]1=Cc2ccccc2C1</smiles>

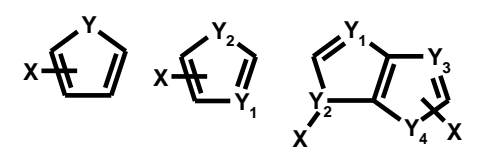<smiles>[Y]1:[Y]c2[Y]ccc2nc1</smiles><smiles>[Y]1nc2[Y]ncn2c2nccnc12</smiles>

$X=H, A l k$, Håt, OAlk, $N(A \mid k)_{2}$,
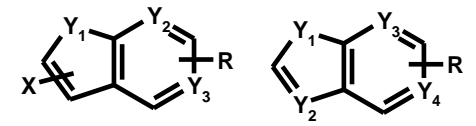

$\mathrm{Y}=\mathrm{S}, \mathrm{O}, \mathrm{N}$

$R, R_{1}, R_{2}=H, A r$, Het Alk, OAlk, N(Alk)

Figure 9<smiles>CCC(=O)c1c(-c2ccco2)oc2ccccc2c1=O</smiles><smiles>O=C/C=C/c1oc(-c2ccccc2)c2c(=O)c3ccccc3oc12</smiles>

\section{Scheme 3}


Table 4. Spectral-kinetic characteristics of the phototransformations for chromones in toluene

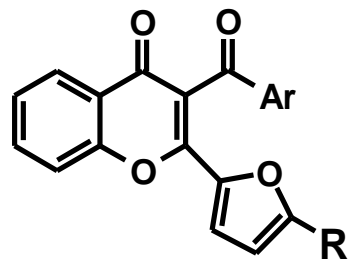

\begin{tabular}{ccccccc}
\hline Code & $\mathrm{R}$ & $\mathrm{Ar}$ & $\begin{array}{c}\lambda_{\mathrm{A}}{ }^{\max }, \\
\mathrm{nm}\end{array}$ & $\begin{array}{c}\lambda_{\mathrm{B}}{ }^{\max }, \\
\mathrm{nm}\end{array}$ & $\begin{array}{c}\lambda_{\mathrm{B}}{ }^{\mathrm{fl}, \max }, \\
\mathrm{nm}\end{array}$ & $\begin{array}{c}\Delta \mathrm{I}_{\mathrm{B}}{ }^{\mathrm{fl}}, \\
\text { a.u. }\end{array}$ \\
\hline XVII.1 & $\mathrm{H}$ & $\mathrm{Ph}$ & 313 & 415 & 490 & 100 \\
XVII.2 & $\mathrm{Me}$ & $\mathrm{Ph}$ & 327 & 418 & 495 & 331 \\
XVII.3 & $\mathrm{H}$ & 2-Furyl & 310 & 368,425 & 505 & 672 \\
XVII.4 & $\mathrm{Me}$ & 2-Furyl & 325 & 373,425 & 508 & 317 \\
XVII.5 & $\mathrm{H}$ & Thiophen-2-yl & 306 & 370,440 & 498,520 & 400 \\
XVII.6 & $\mathrm{Me}$ & Thiophen-2-yl & 327 & 372,435 & 520 & 450 \\
\hline
\end{tabular}

Note: $\lambda_{A}{ }^{\max }$ and $\lambda_{B}{ }^{\max }$ are the maxima of absorption bands for the initial substance $A$ and photoproduct $B$, respectively; $\lambda_{B}{ }^{\mathrm{fl} \text {, max }}$ is the fluorescence maximum of the photoproduct $B, \Delta \mathrm{I}_{\mathrm{B}}{ }^{\mathrm{fl}}$ is the maximal photoinduced change of fluorescence intensity at the fluorescence maximum under excitation by visible light absorbed by photoproduct B.

Analysis of the data given in Table 4 shows that the phenyl- substituted chromones (XVII.1 and XVII.2) show the shortest-wavelength absorption- and fluorescence bands of the photoproduct. The introduction of a methyl group into the furyl fragment enhances the fluorescence intensity. Further enhancement of the fluorescence intensity is induced by the introduction of a second furyl fragment (XVII.3). Simultaneously, the absorption and fluorescence bands of the photoproduct are shifted bathochromically. In this case, the introduction of a methyl group into the furyl fragment (compound XVII. 4) entails, conversely, a decrease in the fluorescence intensity. This may indicate that, apart from the electronic influence on the fluorescence properties, the steric factor should also be taken into account. The most pronounced effect on the positions of the absorption and fluorescence bands comes from the replacement of the phenyl fragment by the thienyl one (compound XVII.5 and XVII.6). These bands experience further bathochromic shift. The fluorescence intensity of these compounds increases sharply in a polymer matrix (Figure11). The spectral characteristics of the chromones were in good agreement with the characteristics of the modern lasers. It opens up prospects for using these compounds as light-sensitive components of recording media for multilayer ODs with fluorescent optical data readout. 


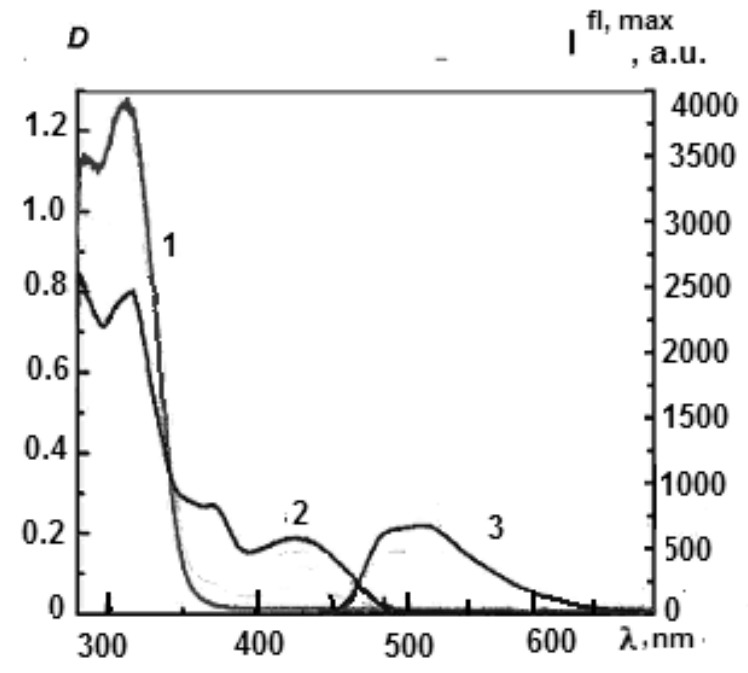

Figure 10. Absorption spectra $(1,2)$ and fluorescence (3) for the compound XVII.3 in toluene before (1)- and after - UV irradiation at $313 \mathrm{~nm}(2,3)$. The excitation irradiation of fluorescence is at $430 \mathrm{~nm}$.

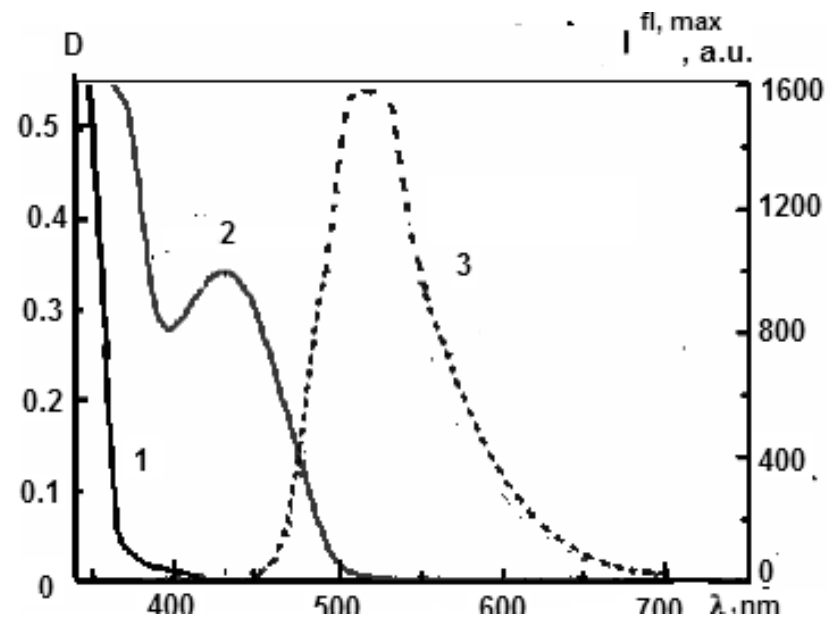

Figure 11. Absorption spectra (1,2) and fluorescence (3) for compound XVII.5 in PMMA (polymethylmethacrylatt) film before (1), and after consecutive UV irradiation (2,3). The excitation irradiation of fluorescence is at $440 \mathrm{~nm}$.

Photochromic heterocyclic spirocompounds for chemosensors ${ }^{42-50}$

The complexation between the molecules of photochromic spirocompounds and metal ions is due to the possibility of electrostatic interaction between the metal cation and the anionic sites of the molecules, including the phenoxide oxygen of the photoinduced merocyanine form which is involved in the thermal closure of the pyran ring (scheme $7, \mathrm{Z}=\mathrm{CH}, \mathrm{N}) .^{2-4}$ 

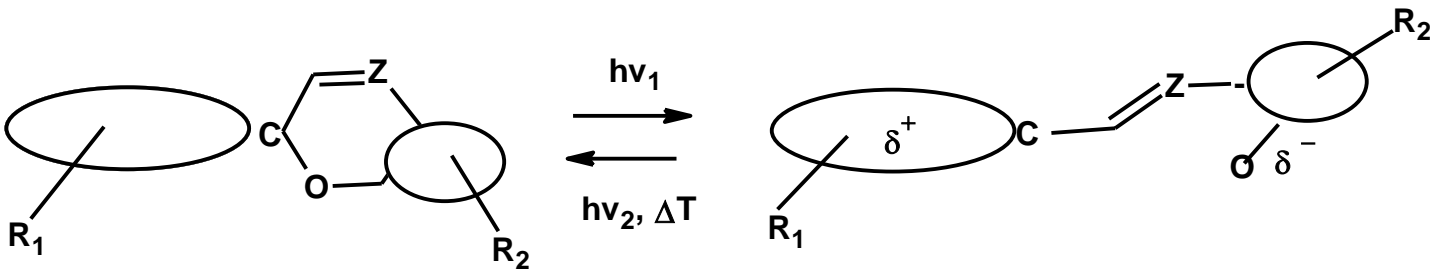

\section{Scheme 4}

The strength of the complexes, and hence the change in the spectral-kinetic characteristics of photochromic compounds, depends on both the structure of the spiro- compound and the nature of the metal. Owing to their different electronic structures, the two forms of a photochromic compound have different complexation abilities towards metal ions. As a result, photoprocesses involving photochromic spiro- compounds may provide photocontrolled reversible binding of the metal cations present in solution. The photocontrolled complexation with various metal cations may be of considerable interest for many fields of science including chemistry, biology, and environmental protection.

The development of methods for chemical analysis of metal ions present in solutions of photochromic compounds should ensure high sensitivity, selectivity, reversibility, and the possibility of visualization of spectral changes that take place upon complexation due to the use of photochromic spiro- compounds with different spectral characteristics of the photoinduced form (Figure 12). The sensitivity of chemosensors based on spiro- compounds can be rather high, because the photoinduced form of these compounds, in particular of nitro- substituted spiropyrans, has fluorescence properties (Figure 13). ${ }^{50}$

The study of complexation between spiro(indoline-naphthooxazines) XVIII (Figure 14) and metal ions showed that the magnitude and direction of the spectral shift for the colored merocyanine form for compounds XVIII.1 to XVIII.4 depend on the type of substituents (Figure 15). The blue shift of the photo-induced absorption band observed for compounds XVIII.2 and XVIII.3, as compared with the compound XVIII.1, indicates a lower polarizability of the excited state of 6'-substituted molecules with electron-donating substituents. Conversely, an electronwithdrawing substituent (in compound XVIII.4) gives rise to the red-shift of the photo-induced absorption band. This is indicative of a higher polarizability of the excited state of XVIII.4. The observed spectral shifts are due to the nature of anionic sites of the spiro-oxazine substituent. Added metal ions reduce the donating ability of the piperidine group, resulting in a bathochromic (red) shift of the photo-induced absorption band. Meanwhile, added metal ions diminish the electron-withdrawing ability of the cyano group, which gives rise to a hypsochromic (blue) spectral shift of photoinduced absorption. In accordance with the ionic potential of metals the position of the photoinduced absorption bands depends on the energy of electrostatic interaction between the merocyanine form and the metal ion, and increases in the order:

$$
\mathrm{Li}^{+}<\mathrm{Ba}^{2+}<\mathrm{Ca}^{2+}<\mathrm{Mg}^{2+}<\mathrm{La}^{3+}<\mathrm{Tb}^{3+}
$$


In the case of low ionic potentials, the shift of photo-induced absorption of complexes is insignificant. The effect becomes important in the case of high ionic potentials.

The value of $\mathrm{k}_{\mathrm{BA}}$ for compounds XVIII.1 - XVIII.4 depends appreciably on the type of 6'substituent (Figure 16). The values of $\mathrm{k}_{\mathrm{BA}}$ are higher for compounds with electron-donating substituents (XVIII.2, XVIII.3) and lower for compound XVIII.4 with an electron-withdrawing substituent, as compared with unsubstituted compound SO 1. In the presence of metal cations the $\mathrm{k}_{\mathrm{BA}}$ value diminishes irrespective of the type of substituent. The pace of this decrease is essentially the same for all of the compounds XVIII.1 - XVIII.4, being determined only by the electrostatic properties of ions. Thermal bleaching of the photoinduced absorption band is governed by the extent of interaction between metal ions and the oxygen atom in the merocyanine colored form.

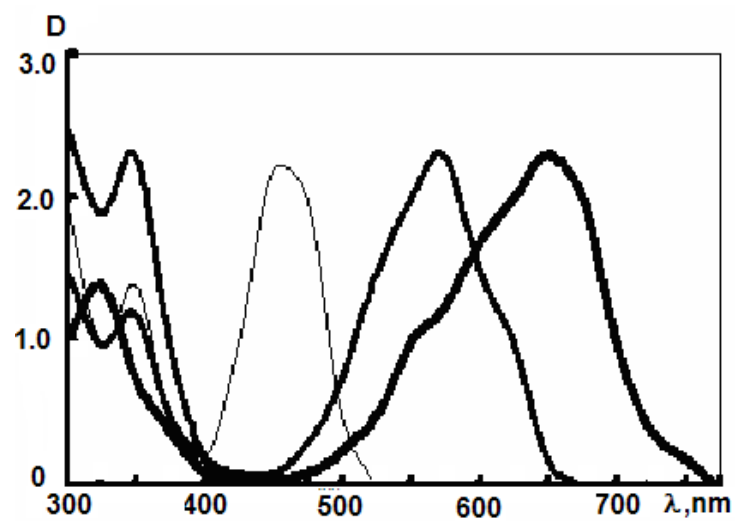

Figure 12. Absorption spectra for the photoinduced merocyanine forms of nitro-substituted spiropyrans in toluene.

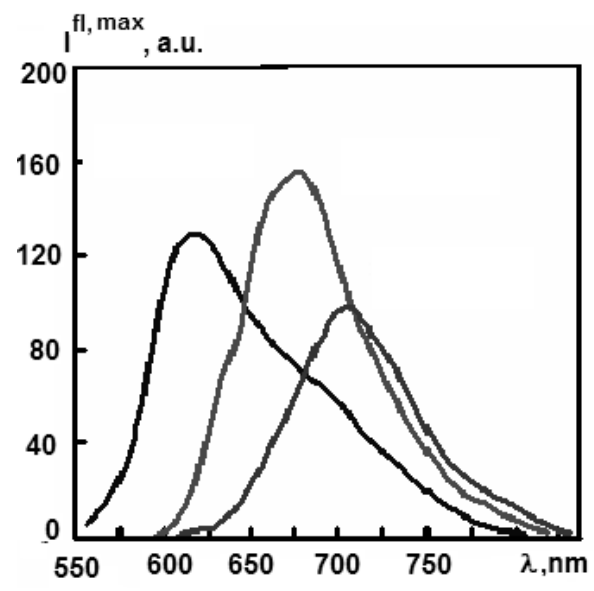

Figure 13. Fluorescence spectra for the photoinduced merocyanine forms of nitro-substituted spiropyrans in toluene. 
XVIII1:R=H
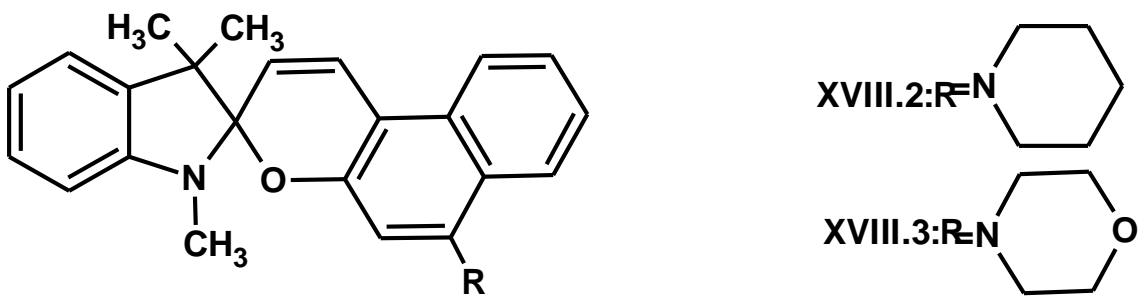

XVIII.4:R=CN

\section{Figure 14}

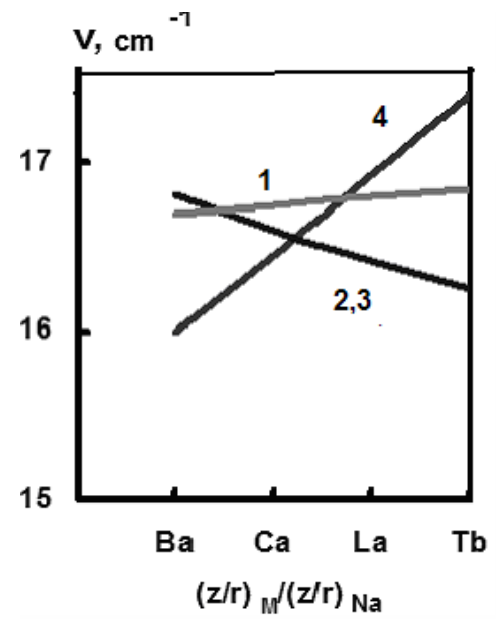

Figure 15. The values of $\lambda_{B}{ }^{\max }$ for compounds XVIII.1 (1), XVIII.2 (2), XVIII.3 (3) and XVIII. 4 (4) as functions of the ionic potential of the metal cation (acetonitrile, $\mathrm{C}=2 \times 10^{-4} M$, $[$ Met $\left.]=2 \times 10^{-2} M\right)$.

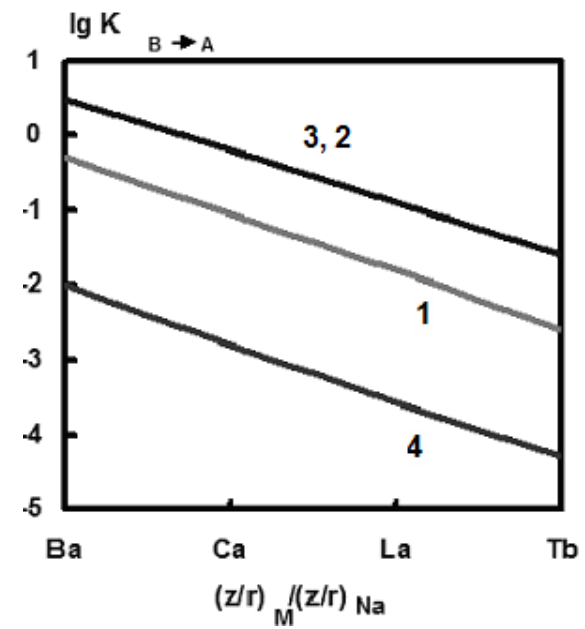

Figure 16. The thermal bleaching constant (log $\mathrm{k}_{\mathrm{BA}}$ ) for compounds XVIII.1 (1), XVIII.2 (2), XVIII.3 (3) and XVIII.4 (4) as a function of the ionic potential of the metal cation (acetonitrile, $\left.\mathrm{C}=2 \times 10^{-4} M,[\mathrm{Met}]=2 \times 10^{-2} M\right)$. 
Unlike the nitro-substituted indoline spirooxazines XVIII, the nitro-substituted benzothiazoline spiropyran molecules XIX (Figure 17) have a thermally stable merocyanine form. The lifetime of the photoinduced merocyanine form is several orders of magnitude longer than those of other known spiro- compounds. This is due to the influence of both the electronic properties of substituent $\mathrm{R}_{3}$ and steric hindrance of this substituent to the dark trans-cis isomerization to the spiropyran form. This fact made it possible to study the formation of complexes between metal ions and molecules in both the spiropyran and merocyanine forms, independently of each other.

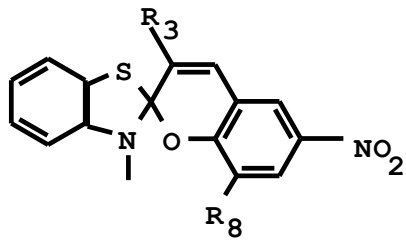

Figure 17. $\mathrm{R}_{3}=\mathrm{R}_{8}=\mathrm{OCH}_{3}(X I X .1) ; \mathrm{R}_{3}=\mathrm{O}\left(\beta-\mathrm{C}_{10} \mathrm{H}_{9}\right) ; \mathrm{R}_{8}=\mathrm{OCH}_{3}(X I X .2)$.

The complexation of the spiropyran form with metal ions is caused by the formation of metal chelates with participation of the benzothiazoline sulfur atom and the substituent $\mathrm{R}_{3}$. The formation of complexes is accompanied by the appearance of the new absorption band with a maximum at $405 \mathrm{~nm}$ (Figure 18). The photoinduced merocyanine form of this compound is responsible for an absorption band in the visible region, with a maximum at $575 \mathrm{~nm}$ (Figure 19, curve 1). The introduction of $\mathrm{Ba}^{2+}$ ions leads to disappearance of this band, and gives rise to a new absorption band having a maximum at $505 \mathrm{~nm}$, indicating the complex formation (Figure 19, curves 2-5).

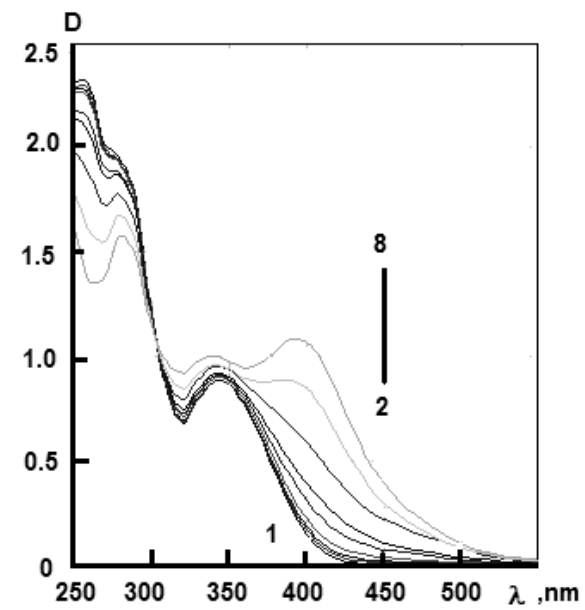

Figure 18. Absorption spectra of the spiro- form for the compound XIX.1 in acetonitrile before (1), and after (2-8) addition of $\mathrm{Mg}^{2+}$ ions, with the concentration ratio of the metal ion $\left(\mathrm{C}_{\mathrm{M}}\right)$ to the photochromic compound $\left(\mathrm{C}_{\mathrm{Ph}}\right), \mathrm{C}_{\mathrm{M}} / \mathrm{C}_{\mathrm{Ph}}$, varying from 5 to 1000 . 


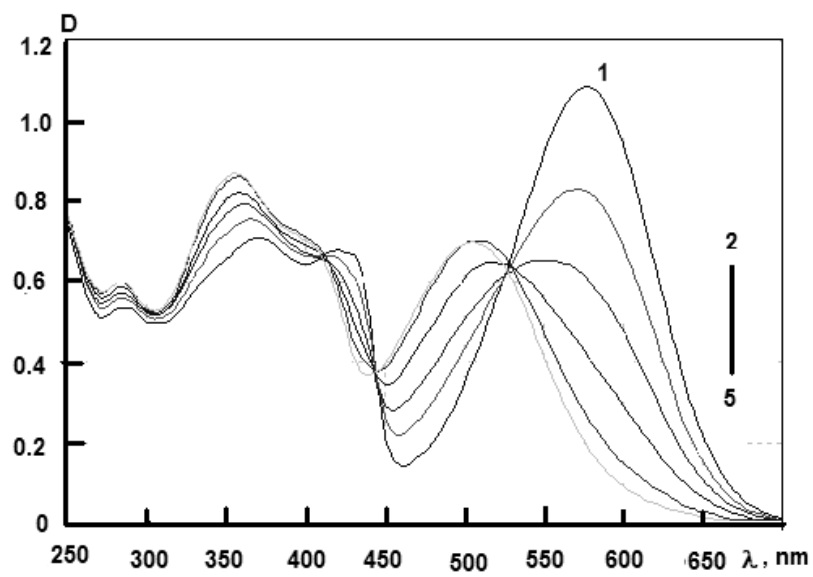

Figure 19. Absorption spectra of the photo-induced merocyanine form of the compound XIX.1 in acetonitrile, before (1), and after (2-5), addition of $\mathrm{Ba}^{2+}$ ions with $\mathrm{C}_{\mathrm{M}} / \mathrm{C}_{\mathrm{Ph}}$ varying from 0.005 to 1.0 .

The position of the absorption band of the photoinduced form depends on the electrostatic properties of the metal cations present in solutions (Table 5). It follows from Table 5 that the shift of the absorption band of the photoinduced merocyanine form depends on the efficiency of interaction of the metal cation with the phenoxide oxygen arising upon photodissociation of the $\mathrm{C}-\mathrm{O}$ - bond in the pyran heterocycle. The intensity of absorption bands decreases following the decrease in the positive charge density of the metal cation.

Table 5. Spectral properties of the photoinduced merocyanine form of photochromic benzothiazoline spiropyrans in acetonitrile, with and without metal ions

\begin{tabular}{cccc}
\hline Compound & Ion & $\lambda_{\mathrm{B}}{ }^{\max }, \mathrm{nm}$ & $\Delta \lambda_{\mathrm{B}}{ }^{\max }, \mathrm{nm}$ \\
\hline XIX.1 & None & 575 & -70 \\
& $\mathrm{Ba}^{2+}$ & 505 & -90 \\
$\mathrm{Ca}^{2+}$ & 485 & -115 \\
& $\mathrm{Mg}^{2+}$ & 460 & -135 \\
\hline $\mathrm{Eu}^{3+}$ & 440 & -35 \\
& $\mathrm{None}^{2+}$ & 590 & -95 \\
& $\mathrm{Ba}^{2+}$ & 515 & -110 \\
$\mathrm{Ca}^{2+}$ & 495 & -150 \\
& $\mathrm{Mg}^{2+}$ & 480 & \\
& $\mathrm{Eu}^{3+}$ & 440 &
\end{tabular}

Unlike nitro-substituted benzothiazoline spiropyrans, naphthopyrans XX (Figure 20) with electron-donating substituents show a bathochromic shift of the absorption bands upon reaction of metal ions with molecules of the photoinduced merocyanine form (Figure 21, Table 6). 


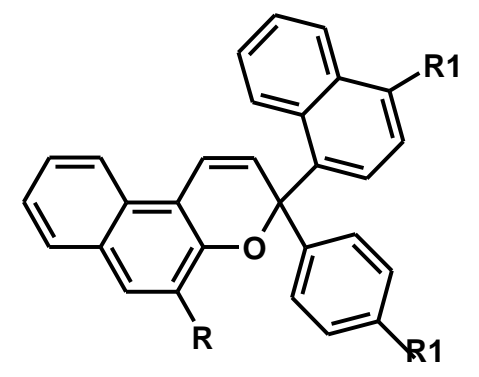

Figure 20. For (XX.1), $\mathrm{R}=\mathrm{H} ; \mathrm{R}_{1}=\mathrm{N}\left(\mathrm{CH}_{3}\right)_{2}$; for $(X X .2), \mathrm{R}=\mathrm{CONH}\left(\mathrm{C}_{6} \mathrm{H}_{4}\right) \mathrm{OCH}_{3} ; \mathrm{R}_{1}=\mathrm{N}\left(\mathrm{CH}_{3}\right)_{2}$

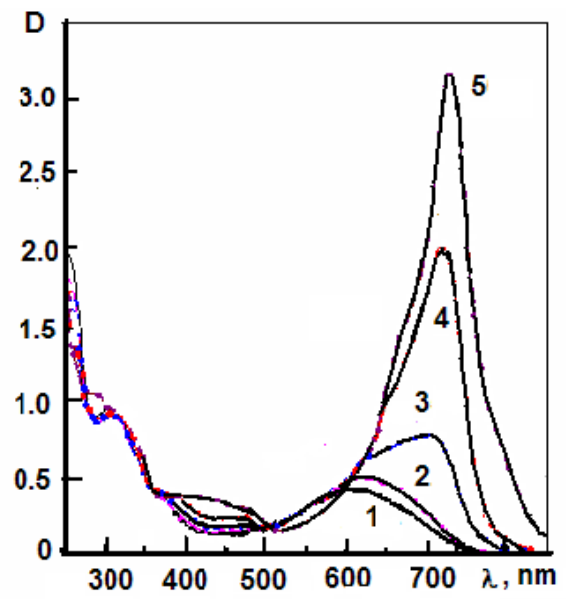

Figure 21. Absorption spectra for the photoinduced merocyanine form of the compound XX.2 in acetonitrile in the absence (1) and in the presence of $\mathrm{Ba}^{2+}(2), \mathrm{Ca}^{2+}(3), \mathrm{Mg}^{2+}$ (4), $\mathrm{Eu}^{3+}$ (5). $\mathrm{C}_{\mathrm{M}} / \mathrm{C}_{\mathrm{Ph}}=100$

Table 6. Spectral properties of the photoinduced merocyanine form of photochromic naphthopyrans in acetonitrile with and without metal ions

\begin{tabular}{cccc}
\hline Compound & Ion & $\lambda_{\mathrm{B}}{ }^{\max }, \mathrm{nm}$ & $\Delta \lambda_{\mathrm{B}}{ }^{\mathrm{max}}, \mathrm{nm}$ \\
\hline XX.1 & None & 540 & \\
& $\mathrm{Mg}^{2+}$ & 680 & +140 \\
& $\mathrm{La}^{3+}$ & 705 & +165 \\
& $\mathrm{~Tb}^{3+}$ & 710 & +170 \\
\hline XX.2 & None & 615 & +65 \\
& $\mathrm{Ba}^{2+}$ & 680 & +95 \\
& $\mathrm{Ca}^{2+}$ & 710 & +105 \\
& $\mathrm{Mg}^{2+}$ & 730 & +115 \\
\hline $\mathrm{Eu}^{3+}$ & & \\
\hline
\end{tabular}


Analysis of the results of a spectral kinetic study of the complexation of the photoinduced merocyanine forms of various types of spiro-compounds shows that their spectral changes are selective with respect to metal ions, and the intensity of the absorption bands of the colored form depends on the nature of the metal ions. Since the merocyanine forms of many spiro-compounds possess fluorescence properties, they can be used as reversible photocontrolled components of the work surfaces of chemosensors and chemochips.

\section{Conclusions}

Photochromic compounds (diarylethenes, fulgimides, quinones) meet the requirements for preparation of multilayer recording media for 3D two-photon bitwise working optical memory. For making recording media for bitwise archive optical memory, chromones that form fluorescent products as a result of irreversible photochemical reaction were synthesized. Photochromic compounds (spiro- compounds, quinones, diarylethenes) may be used as photosensitizers in holographic photo-polymerizable recording media for 3D holographic archive optical memory. Spiro-compounds may permit the development of photo-controlled reversible selective metal sensors and chips with wide functional possibilities.

\section{Experimental Section}

General Procedures. The studies were carried out in solutions. A.C.S. spectrophotometric grade toluene and acetonitrile were used as solvents. The absorption spectra of the initial and photoinduced forms of photochromic compounds were measured on Shimadzu UV-VIS and Cary Bio50 (Varian) spectrophotometers in the range $200-800 \mathrm{~nm}$ in 3-mm thick cells. For investigation of the absorption spectra of photofluorescent compounds, a USB2000 (Ocean Optics) fiber optic spectrometer and $3 \mathrm{~mm}$ cells were used. The compound concentration in solution was, most often, $C=2 \times 10^{-4} M$.

The photo-induced colored forms of photochromic compounds were produced by photoexcitation of solutions with the light of a DRSh-250 mercury lamp through a UV filter separating the radiation at the wavelength of the absorption band of the initial form . The photocoloration kinetics for solutions were measured at the wavelength of the absorption maximum of the photoinduced form arising on UV irradiation of solutions of these compounds pre-bleached by visible light.

The photo-bleaching kinetics were studied with irradiation of pre-colored solutions of these compounds with the light of the DRSh-250 mercury lamp in the visible region through glass filters transmitting at the wavelength of the absorption band of the photoinduced form. The photocoloration and photobleaching processes before the onset of effective photodecomposition 
are described by first-order kinetics, as reversible phototransformations took place only between the initial and photoinduced forms.

The kinetic curves for the photodecomposition of photochromic compounds were used for quick evaluation of the recurrence of photochromic transformations under high-intensity radiation. The photodecomposition of solutions was characterized by the time it took for the absorbance attained in the photostationary state at the absorption maximum of the photoinduced form to halve under continuous irradiation with unfiltered light from the DRSh-250 lamp.

All kinetic measurements were carried out under identical experimental conditions with comparable UV- and visible- incident radiation intensities, which made possible comparative analysis of the results.

Attention was focused on the stability of di-hetarylethenes and fulgimides against irreversible phototransformation (photodegradation), because this feature determines the recurrence of photochromic transformations between the open and cyclic forms during optical data recording and erasure. The spectral characteristics found for the light-sensitive compounds were used to determine the conformity between the absorption maxima of both forms, and the wavelengths of radiation for the existing lasers.

The photo-induced absorbance at the absorption maximum of the cyclic form existing in photoequilibrium under UV radiation was also measured. This was used to estimate the relative light -sensitivities of compounds to recording UV radiation. The ratio of the photocoloration and photobleaching rate constants was used for comparative evaluation of the efficiency of these processes.

Kinetic data on thermal isomerization of the photoinduced forms of dihetarylethenes and fulgimides were obtained by periodic measurement (every few days) of the absorption spectra of solutions. During intervals between the measurements the solutions were stored in the dark.

Fluorescence spectra were recorded on a Cary Eclipse spectrofluorimeter (Varian). The working concentration of light-sensitive compounds in solutions was $\mathrm{C}=4 \times 10^{-5} \mathrm{M}$. The measurements were carried out in 1-cm thick quartz cells. Solutions were irradiated by filtered light of the DRSh-250 lamp and a LC-4 Hamamatsu spot light source.

\section{Acknowledgements}

This study was supported by the Presidium of the Russian Academy of Sciences.

\section{References}

1. Barachevsky, V. A. Final Program and Proceedings, ICIS'06 International Congress of Imaging Science. May 7-11, 2006; Rochester: New York, USA, 2006, p 435.

2. Photochromism; Brown, G. H., Ed.; Wiley: Interscience, N.Y., 1971. 
3. Barachevsky, V. A.; Lashkov, G. I.; Tsekhomsky, V. A. Fotokhromism i ego primenenie (Photochromism and its Application); Khimiya: Moscow, 1977.

4. Organic Photochromic and Thermochromic Compounds; Crano, J. C.; Guglielmetti, R. J. Eds.; Plenum Press: New York and London, 1999.

5. Hirshberg, Y. J. Am. Chem. Soc.1956, 78, 2304.

6. Irie, M.; Mohri, M. J. Org. Chem. 1988, 53,803.

7. Parthenopoulos, D. A.; Rentzepis, P. M. Science 1989, 245, 843.

8. Mandjikov, V. F.; Darmanian, A. P.; Barachevsky, V. A.; Gerulaitis, Yu. N. Optics and Spectroscopy. 1972, 32, 412 (Russ.).

9. Irea, M. Chem. Rev. 2000, 100, 1685.

10. Yokoyama, Y. Chem. Rev. 2000, 100, 1717.

11. Barachevsky, V. A. In: Organic Photochromic and Thermochromic Compounds; Crano J. C. and Guglielmetti R. J., Eds, Plenum Press: New York, 1999; Vol. 1.

12. Shirinian, V. Z.; Krayuskin, M. M.; Barachevsky, V. A.; Beleb'kii, L. I.; Shimkin, A. A.; Strokach, Y. P. Mendeleev Communications 2004, 202.

13. Strokach, Y. P.; Valova, T. M.; Golotyuk, Z. O.; Barachevsky, V. A.; Yarovenko, V. N.; Kalik, M. A.; Krayushkin, M. M. Optics and Spectroscopy 2005, 99, 714.

14. Strokach, Y. P.; Valova, T. M.; Golotyuk, Z. O.; Barachevsky, V. A.; Kuznetsova, O. Yu.; Yarovenko, V. N.; Semenov, S. L.; Zavarzin, I. V.; Shirinian, V. Z.; Krayushkin, M. M. Optics and Spectroscopy 2005, 99, 573.

15. Krayushkin, M. M.; Kalik, M. A.; Kozhinov, D. V.; Martynkin, A. Y.; Strokach, Y. P.; Barachevsky, V. A. Chem. Heterocyclic Compounds 2005,41, 312.

16. Belen'kii, L. I.; Kolotaev, A. V.; Shirinyan, V.Z.; Krayushkin, M. M.; Strokach, Yu P.; Valova, T. M.; Golotyuk, Z. O.; Barachevsky, V. A. Chemistry of Heterocyclic Compounds 2005, 41, 86 .

17. Belen'kii, L. I.; Kolotaev, A. V.;. Shirinyan, V. Z.; Krayushkin, M. M.; Strokach, Yu. P.; Valova, T. M.; Golotyuk, Z. O.; Barachevskii, V. A. ChemInform 2005, 36, 46.

18. Barachevsky, V. A.; Strokach, Y. P.; Krayushkin, M. M.; Mol. Cryst. Liq. Cryst. 2005, 430, 181.

19. Yarovenko, V. N.;Es'kov, A. A.; Semenov, S. L.; Zavarzin, I. V.; Kadentsev, V. I.; Kalik, M. A.; Krayushkin, M. M.; Strokach, Yu. P.; Valova, T. M.; Golotyuk, Z. O.; Barachevsky, V. A. Russian Chemical Bulletin 2005, 54 (12), 2790.

20. Barachevsky, V. A.; Strokach, Yu. P.; Valova, T. M.; Puankov, Yu. A; Krayushkin, M. M. J. Phys .Org. Chemistry 2007, 20 (11), 1007.

21. Barachevsky, V. A.; Strokach, Yu. P.;Valova, T. M.; Puankov, Yu. A.; Krayushkin, M. M. Opt. Memory \& Neural Networks 2007, 16, 51.

22. Krayushkin, M. M.; Migulin, V. A.; Yarovenko, V. N.; Barachevskii, V. A.; Vorontsova, L. G.; Starikova, Z. A.; Zavarzin, I. V.; Bulgakova, V. N. Mendeleev Commun. 2007, 17, 125.

23. Strokach, Yu.P.; Kobeleva, O. I.; Valova, T. M.; Barachevsky, V. A.; Pashchenko, D. V.; Lichitski, B. V.;. Krayushkin, M. M. Optics and Spectroscopy 2007, 103(6), 936. 
24. Markova, G. D.; Vasnev, V. A.;Keshtov, M. L.; Khokhlov, A. R.; Krayushkin, M. M.; Ivanov, S. N.; Valova, T. M.; Dunaev, A. A.; Strokach, Yu. P.; Barachevsky, V. A.; Vorontsova, L. G.; Starikova, Z. A. Polymer Science, Series B. 2006, 48 (1-2), 18.

25. Dunaev, A. A.; Alfimov, M. V.; Barachevsky, V. A.; Zavarsin, I. V.; Ivanov, S. N.; Keshtov, M. L.; Kovalev, A. I.; Krayushkin, M . M.; Pyankov, Y . A.; Rusanov, A . L.; Strokach, Y . P.; Yarovenko, V . N. US Patent Application 2006/0079653, 2006.

26. Barachevsky, V . A.; Krayushkin, M. M. Final Program and Proceeding, 21st International Conference on Digital Printing Technology, September 18-23; 2005. Baltimore, Maryland, USA, 2005, p.24.

27. Barachevsky, V. A.;Krayushkin, M. M., 2005 Beijing International Conference on Imaging: Technology \& Applications for the $21^{\text {st }}$ Century. Beijing, China, May 23-26, 2005; p 30.

28. Barachevsky. V. A. Final Program and Proceedings. ICIS'06 International Congress of Imaging Science.May 7-11, 2006, Rochester, New York, USA. 2006; p 435.

29. Krayushkin, M. M.; Barachevsky, V. A.; Irie, M. Heteroatom Chem. 2007, 18, 557.

30. Krayushkin, M. M; Barachevsky, V. A.; Irie, M. ChemInform. 2007, 38, 39.

31. Barachevsky; V. A.; Strokach; Yu. P.; Puankov; Yu. A.; Yu. A.. Grebennikov; Yu. A.; Kiyko; V. V.; Krayushkin, M. M. Proc. SPIE 2007, 6796, 67961V.

32. Krayushkin, M. M.; Shorunov, S. V.; Luyksaar, S. I.; Strokach, Yu. P.; Valova, T. M.; Golotyuk, Z. O.; Barachevsky, V. A. Chemistry of Heterocyclic Compounds 2006, 42(8), 1012.

33. Barachevsky, V. A.; Kiyko, V. V.; Krayushkin, M. M.; Lyiksaar, S. I.; Ofiserov, E. N.; Puankov, Y. A.; Stoyanovich, F. M.; Strokach, Y. P.; Valova, T. M. Patent Application, WO 2006/037279, 2006.

34. Barachevsky, V. A.; Peredereeva, S. I.; Nesterenko, D. V.; Lyubimov, A. V.; Salakhutdinov, V. R.; Sokolyuk, N. T.; Mikaelian, A.L. Patent Application WO 2005/049764, 2005.

35. C3D, White paper. Tech. Rep., Constellation 3D, 2000, http://www.c-3d.net/whitepaper.html.

36. Dvornikov, A. S.; Rentzepis P. M. Opt. Commun. 1997, 136, 1.

37. Dvornikov, A. S.; Taylor, C. M.; Liang, Y. C.; Rentzepis, P. M. J. Photochem. Photobiol. A. Chemistry 1998, 112, 39.

38. Alfimov, M. V.; Nazarov, V. B. Disp. Technol. 1986, 1, 119.

39. Barachevsky, V. A.; Alfimov, M. V.; Nazarov, V. B. Proc. SPIE 1998, 3468, 293.

40. Barachevsky, V. A.; Alfimov, M. V.; Nazarov, V. B. Opt. Memory \& Neural Networks 1998, 7, N 3, 205.

41. Barachevsky, V. A.; Alfimov, M. V.; Nazarov, V. B. Sci. Appl. Photo. 1999, 41(3), 299.

42. Fedorova, O. A.; Gromov, S. P..; Strokach, Yu. P.; Pershina, Yu. V.; Sergeev, S. A.; Barachevsky, V. A.; Pepe, G.; Samat, A.; Guglielmetti, R.; Alfimov, M. V. Russian Chemical Bulletin 1999, 48(10), 1950. 
43. Fedorova, O. A.; Gromov, S. P.; Pershina, Y. V.; Sergeev, S. A.; Strokach, Y. P.; Barachevsky, V. A.; Alfimov, M. V.; Pepe, G.; Samat, A.; Guglielmetti, R. J. Chem. Soc. Perkin Trans. 2. 2000, 563.

44. Barachevsky, V. A. Mol. Cryst. Liq. Cryst. 2000, 344, 277.

45. Strokach, Yu.P.; Valova, T. M.; Barachevsky, V. A.; Alfimov, M. V.; Lokshin, V.; Guglielmetti, R.; Samat, A. Sci. Appl. Photo. 2000, 41 (6), 491.

46. Strokach, Yu. P.; Valova, T. M.; Arsenov, V. D.; Barachevsky, V. A.; Alfimov, M. V. Sci. Appl. Photo. 2000, 42(6), 531.

47. Barachevsky, V. A. High Energy Chemistry 2003, 17(1), 6.

48. Khodonov, A. A.; Lukin, A. Y.; Laptev, A. V.; Shvets, V. I.; Demina, O. V.; Gromov, S. P.; Vedernikov, A. I.; Strokach, Y. P.; Venidiktova, O. V.; Valova, T. M.; Alfimov, M. V.; Barachevsky, V. A. Mol. Cryst. Liq. Cryst. 2005, 431, 515.

49. Strokach, Yu. P.; Valova, T. M.; Barachevsky, V. A.; Shienok, A. I.; Marevtsev, V. S. Russian Chemical Bulletin 2005, 54 (6), 1477.

50. Ignatin, A. A.; Strokach, Yu. P.; Barachevsky, V. A. Sci. Appl. Photo. 1998, 40(3), 243.

51. Barachevsky, V. A. J. Fluorescenc, 2000, 10(2), 185. 